\title{
Factors Influencing Acceptance of Mobile money Applications in Enterprise Management: A Case Study of Micro and Small Enterprise Owners in Kisumu Central Business District, Kenya
}

\author{
Edwin Omol ${ }^{1}$, Dr. Silvance Abeka ${ }^{2}$, Fred Wauyo ${ }^{2}$ \\ Department of Information and Communication Technology, Kisii University, Kisii, Kenya ${ }^{1}$ \\ School of Informatics and Innovative Systems, Jaramogi Oginga Odinga University of Science \& Technology, \\ Bondo, Kenya ${ }^{2}$
}

\begin{abstract}
The research aimed at determining factors influencing acceptance of mobile applications in enterprise management specifically testing whether relationship exists between demographic features, Perceived Usefulness (PU), Perceived Ease of Use (PEOU) and Perceived Risk (PR); and acceptance of mobile money payment among micro and small enterprises in Kisumu City, Kenya. The research exhibited descriptive correlational research design enabling the researcher to determine the strength of relationship between the variables of the study and the study employed simple random and purposive sampling technique for selection of the samples. The questionnaires were administered by the researcher with the help of two research assistants to the MSE's Owners in Kisumu City CBD. A total of 271 respondents returned their questionnaires, resulting in a response rate of $95.8 \%$ which was considered satisfactory for subsequent analysis. Due to the quantitative nature of the study, the results were analyzed with statistical tools using mean, mode, median, frequency tables and multiple regression. The results indicated that Demographic features, PU, PEOU and PR are significantly related to acceptance of MMP. PEOU was found to be the most influential determinant of acceptance with $\mathrm{r}=0.872, \mathrm{p}$ - value $=0.013$ at $0.05 \%$ significant level. The analysis also revealed that PR on MMP was the major hindrance of users accepting the technology with a negatively strong relationship of $r$ value $=-0.548$ and $\mathrm{p}$ value $=0.003$. The study also established joint contributions of the four independent variables on acceptance of MMP but failed to establish the individual contribution of each independent variable on MMP hence there is need for further studies.
\end{abstract}

Keywords: Mobile Money Payment, Demographic features, Perceived Usefulness, Perceived Ease of Use, Perceived Risk, TAM, Micro and Small Enterprise.

\section{BACKGROUND INFORMATION}

The Communication Authority of Kenya (CAK) through the implementation of "The Kenya Communication Act" has provided an environment that has seen reforms in the telecommunication sector. This has enabled mobile telephony to grow exponentially hence providing base for successful technologies such as mobile banking (Mbanking) and Electronic Money. Moreover, the Kenyan government's policy is to promote and support innovation (Tobbin, 2012). Technology is being used by businesses like MSE's today to enhance growth and competitiveness (Tobbin, 2012) .MSEs are developing new and innovative products to be able to maintain existing customers and to attract new market. One such innovation is the acceptance of mobile money payment. Mobile money has changed the way MSE's perform their operations, this has led to the introduction of cashless mode of payments service facilitating electronic money example is LIPA NA MPESA aimed at lowering transaction risk, cost and reaching a larger number of customers (Mas, Ignacio,
2010;Tobbin,2012). Mobile money provides the potential of increasing efficiency of payments system and expanding access to formal financial services by those who presently lack it. At the same time, it could make banking more convenient and cheaper to those who already have bank account (Tossy, 2014).It's clear that emobile money technology will make Kenya realized its vision of ensuring high level of saving to finance overall investment needs(Kenya's Vision 2030). By using Lipa Na M-PESA, business owners can accept payment of goods and services from their customers. They will also handle less cash and will therefore be less susceptible to risks associated with cash handling such as theft and fake currency. In addition, Lipa Na M-PESA will also help traders enhance business efficiency (Safaricom, 2016).

Although several MSEs in Kenya are adopting mobile money payment, there is little research that focuses on this enormous phenomena .Furthermore, numerous scholars in the developed countries found that mobile money payment 
Vol. 6, Issue 1, January 2017

still remains at its infancy stage (Cheah, Teo, et al., 2014).Therefore, this research aimed at exploring the acceptance of mobile money payment by extending Technology Accepting Model (TAM) with demographic features and perceived risk.

\subsection{Statement of the Problem}

The financial system embedded in mobile phone technologies is very important to economic development of a country and have the potential to improve the economic performance of MSE's by affecting almost every structural characteristics of these firms. Kenya's long term plan for national transformation, vision2030, identifies it as one of the six priority sectors under the economic pillar. For Kenyans to effectively access financial services, several MSE's in Kisumu CBD are increasingly accepting and using electronic mobile money besides cash mode of payment. Since mobile money payment acceptance is an innovation that provides the potential of increasing efficiency of formal financial services access, it's important to establish thorough research, factors contributing to the increase in acceptance of mobile money payment by micro and small enterprises especially in Kisumu city CBD, Kenya. This study therefore sought to explore these factors so as to fill the knowledge gap and ascertain that demographic/firm factors, PU, PEOU, and PR together with fore mentioned intervening variables positively affect acceptance of mobile money payment.

\subsection{The purpose and objectives of the Study}

The purpose of this study was to determine factors influencing acceptance of Mobile applications in enterprise management and specifically to test whether relationship exists between demographic features, Perceived Usefulness (PU), Perceived Ease of Use (PEOU), Perceived Risk (PR); and acceptance of mobile money payment among micro and small enterprises in Kisumu City, Kenya. Studies have revealed a seaming willingness among MSE owners in Kenya to accept mobile money payment in due to the numerous advantages they stand to gain.

The objectives of this study were:

i. To establish influence of demographic features on acceptance of mobile money payment in enterprise management.

ii. To establish the relationship between perceived usefulness (PU) and acceptance of mobile money payment in enterprise management.

iii. To establish the relationship between perceived ease of use (PEOU) and acceptance of mobile money payment in enterprise management.

iv. To establish the relationship between perceived risk (PR) and acceptance of mobile money payment in enterprise management.

v. To establish the joint contribution of demographic features, PU, PEOU and PR on acceptance of mobile money payment in enterprise management.

\section{BACKGROUND OF MOBILE MONEY PAYMENT}

Mobile payment or m-payment is any payment where a mobile device is used to initiate, authorize and confirm an exchange of financial value in return for goods and services (Mas \& Ignacio, 2010). Mobile devices in this case include mobile phones, tablets or any other devices that are able to connect to mobile telecommunication networks and enable payment to be made (Mulupi, 2011). Depending on the channels the MNO makes available for providing the service, a consumer may be limited to the use of mobile phone only or all the other mobile devices aforementioned. M-Payments use what is called e-money or m-money to make payment for goods and services.

\subsection{E-Money vs. M-Money}

Is mobile money (m-money) any different from Electronic Money (e-money)? E-money has been described as a broader concept that refers to payments made using the near-field communication (NFC) contactless cards, credit cards, prepaid cards, debit cards, automated teller machines (ATM), as well as mobile phones. Mobile money is seen as a subset of e-money that refers to financial services and transactions made using technologies integrated into mobile phones. These services may or may not be directly tied to a personal account, or linked to ATM, prepaid, debit or credit cards (IFC, 2013). The rapid growth in the use of mobile phones and the lack of access to formal bank services in most African countries are contributing factors to the rapid growth and the use of mobile money services in most parts of the continent. More than one billion customers in developing markets have access to a mobile phone but do not have a formal bank account (Holmes, 2011). Mobile phone penetration in Africa provides the needed platform to reach out to the rural poor and unbanked with a financial service.

\subsection{Technology Acceptance Model (TAM)}

According to Davis (1989), TAM suggests that perceived usefulness (PU) and perceived ease of use (PEOU) are the two most important factors in explaining individuals' user's acceptances and actual usage. Davis (1989) defines $\mathrm{PU}$ as the degree to which a person believes that using a particular system will enhance his or her job performance. Whereas, PEOU refers to the degree to which the persons believes that using the system will be free of effort. "TAM has been extensively tested and validated and is a widely accepted model, which can be modified or extended using other theories or constructs" (Masinge, 2010).Davis (1989) has also found that there is a relationship between users' beliefs about a technology's usefulness and the attitude and the intention to use the technology. However, perceived usefulness exhibits stronger and more consistent relationship with usage than did other variables reported in the literature. In addition, an individual may adopt a technology if he or she perceives it as convenient, useful and socially desirable even though they do not enjoy using 
Vol. 6, Issue 1, January 2017

the technology (Tobbin, 2010). Thus, there might be a possibility of a direct relationship between beliefs and intentions. Subsequent research by Venkatesh (2003) refined the TAM suggesting that the mediating effect of attitude could be excluded as empirical evidence found that the attitude element did not fully mediate the effect of perceived usefulness on intention to use.

The goal of TAM is to provide an explanation of the determinants of information systems acceptance that is general, capable of explaining user behavior across a broad range of end-user computing technologies and user populations, while at the same time being both parsimonious and theoretically justified. Ideally one would like a model that is helpful not only for prediction but also for explanation, so that researchers and practitioners can identify why a particular system may be unacceptable, and pursue appropriate corrective steps. A key purpose of adopting TAM, therefore, is to provide a basis for tracing the impact of external factors (perceived satisfaction, security and performance) on internal beliefs, attitudes, and intentions (acceptance of the system). TAM was formulated in an attempt to achieve these goals by identifying a small number of fundamental variables suggested by previous research dealing with the cognitive and affective determinants of computer acceptance, and using TRA as a theoretical backdrop for modeling the theoretical relationships among these variables.

TAM has been widely used to predict user acceptance and use based on perceived usefulness and ease of use (Banks, 2008). Consequently, TAM was chosen as the appropriate model and was extended to include other factors such as demographic features and perceived risk. Figure 1.1 presents the research Conceptual framework examined in this study and integrates the theoretical perspectives of previous studies discussed above.

\subsection{Conceptual Framework}

The research model proposed by this researcher, as presented in Figure 1.1, extends TAM in the context of Mobile payment based on prior research on technology acceptance. The model posits that user acceptance of Mobile payment is jointly determined by demographic features, perceived ease of use (PEOU), perceived usefulness (PU), and Perceived Risk (PR). Drawing upon other researchers' (Davis et al., 1989; Venkatesh and Davis, 2000) recommendations to include external factors in the model to examine their effects on core beliefs of TAM, the proposed model incorporates the antecedents of PU and PEOU based on previous studies that have extended the TAM. External variables incorporated in the model include demographic features and Perceived risk which are described latter in this chapter.

These two external variables have direct influence on perceived usefulness which in turn has effect on behavioral intention to accept mobile money payment and actual usage of the technology. The attitude construct, which is included in the original model of technology acceptance as a mediating factor between core beliefs and intended behaviour, was later removed from the TAM. The reason for excluding attitude was based on the observation of Davis et al. (1989), which suggested that attitude does not generally intervene between core beliefs (e.g. PEOU and PU) and behavioural intentions.

Exclusion of attitude is in agreement with previous studies that also excluded attitude from the TAM on the basis of their empirical evidence which showed that the attitude did not mediate the influence of the core beliefs (i.e. PEOU and PU) on the behavioural intentions in the TAM (Davis, F. D \&Venkatesh. V., 1996a; Venkatesh and Morris, 2000;; Tossy, 2014). Therefore, the attitude variable is excluded from the model proposed in this research study.

This framework illustrates the interaction between the independent variables and the dependent variables .It shows the relationship between Demographic features, perceived usefulness (PU), perceived ease of use (PEOU), perceived risk (PR) and acceptance of mobile money applications.

The attitude construct, which is included in the original model of technology acceptance as a mediating factor between core beliefs and intended behaviour (see Figure 2.1), was later removed from the TAM. The reason for excluding attitude was based on the observation of Davis et al. (1989), which suggested that attitude does not generally intervene between core beliefs (e.g. PEOU and PU) and behavioural intentions. Exclusion of attitude is in agreement with previous studies that also excluded attitude from the TAM on the basis of their empirical evidence which showed that the attitude did not mediate the influence of the core beliefs (i.e. PEOU and PU) on the behavioural intentions in the TAM (Davis, F. D \&Venkatesh. V., 1996a; Venkatesh and Morris, 2000; Tossy, 2014). Therefore, the attitude variable is excluded from the model proposed in this research study.

However, despite TAM's maturity and validity in different contexts, very little published literature strives to extend its capability to predict individuals' acceptance behaviour about Mobile Money Payment (MMP). A possible rational for this gap may be conceptualisation of the TAM under which individuals' acceptance behaviour can only be predicted with two beliefs: perceived ease of use (PEOU) and perceived usefulness (PU).

The evidence in literature shows that PU and PEOU beliefs are not sufficient; hence, they may not explain individuals' acceptance behaviour in emerging contexts, such as Mobile Money Payment, especially in developing economies such as Kisumu City, Kenya. There is therefore a need for inclusion of any additional factor that can enhance prediction of acceptance of Mobile Money Payment by potential users within MSEs. 


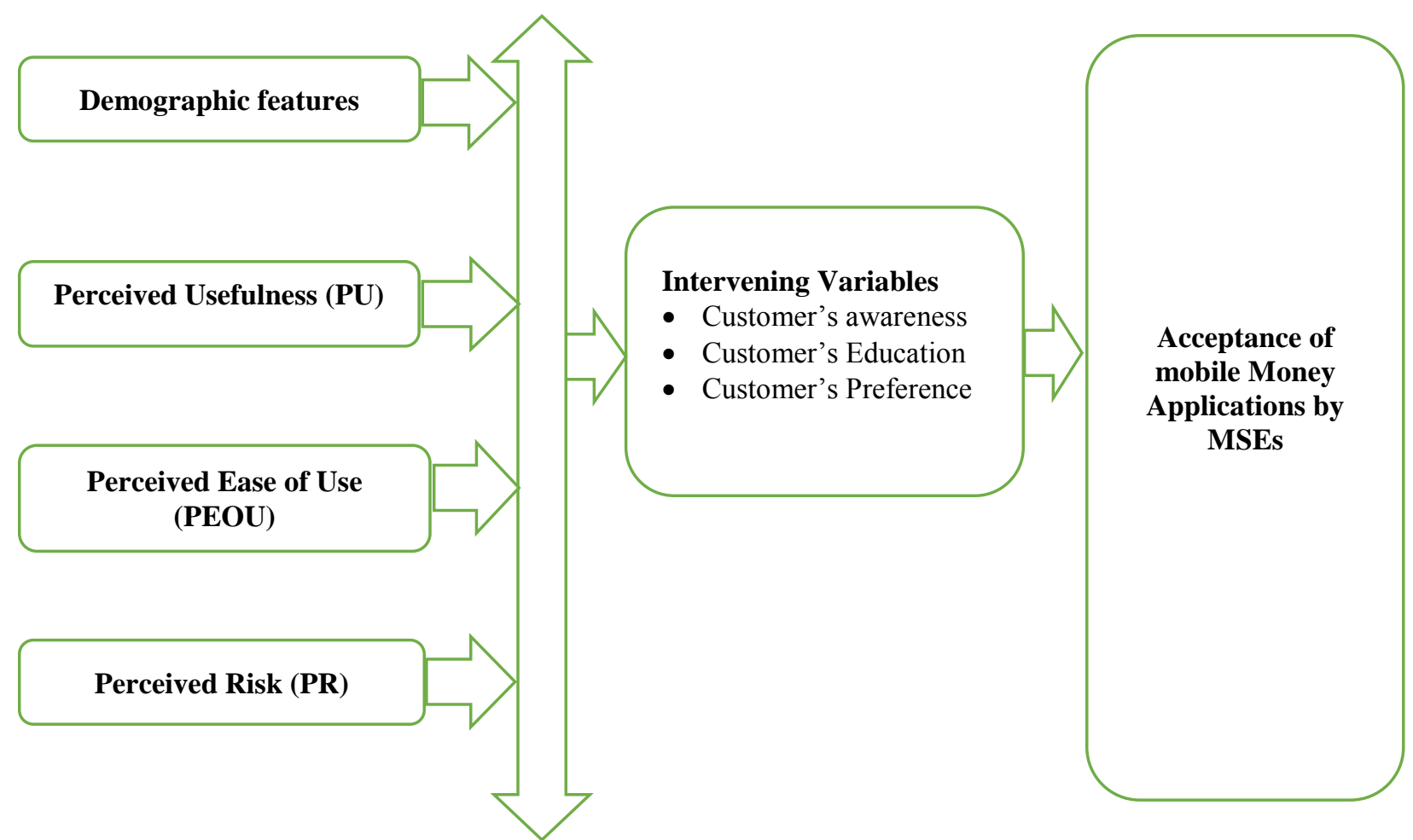

Figure 1.1: Conceptual framework based on TAM with perceived Risk Source: Davis et al., (1989) and modified to suite the research.

\subsection{Summary of Gaps Identified}

The various scholarly sources reviewed registered numerous gaps this study intends to fill. Most studies used case study as contrary to correlational and descriptive needed. research design as will be applied in this study. By reviewing this literature it's also noticed that:-

- Almost all of the researches on M-payments and Mbanking in MSEs and SMEs had been conducted in Europe (UK, Turkey, the Republic of Ireland, Australia, Singapore, Malaysia and Switzerland),
Australia and New Zealand. Only 2 studies were conducted in developing countries.

- The literature was concentrated on some research areas such as Electronic Banking, Technology acceptance, and (up to the knowledge of the researcher) there is no single research on the MSE Owners' Mobile Money Payment's acceptance, demographic features, Perceived Usefulness, Perceived Ease of Use and Perceived Risk of its users or in M-payment in Kenya.

- To the best knowledge of researcher, no previous research has included collectively demographic features, Perceived Usefulness, Perceived Ease of Use, and Perceived Risk in a single TAM- based model, even though these variables are relevant in the context of explaining acceptance of Mobile Money Payment. Thus, the researcher extends the TAM to include user demographic features and Perceived Risk to the model.

Seemingly, this is a major gap in the contemporary research on M-payment acceptance, and its determinants; demographic features, Perceived Usefulness, Perceived Ease of Use and Perceived Risk of its users among MSE owners. Therefore a contribution to the literature is

\section{METHODOLOGY}

This study adopted descriptive correlational research design. Correlational research design was utilized because it enabled the researcher to determine the strength of relationship between demographic features, PU, PEOU, PR and acceptance of mobile money payment with specific reference to the MSEs in Kisumu City CBD. The researcher also determined whether, and or to what degree, a relationship exists between these quantifiable variables.

\subsection{Target Population of the Study}

The population of study was the 964 registered SMEs in Kisumu City CBD as per the Kenya National Chamber of Commerce and Industry Kisumu chapter (KNCCI, 2014). Which were randomly sampled to come up with a representative size that formed the basis of the study .Target population is defined as all the members of a real or hypothetical set of people, events or objects to which a researcher wishes to generalize the results of the research study (Orodho, 2002).

\subsection{Sample Size}

Yamane (1967) simplified formula was applied to calculate the sample sizes since the population under study is less than ten thousand. The study used a $95 \%$ confidence 
level, this means that if the same population is to be sampled on numerous occasions and interval estimates are made on each occasion, the resulting intervals would bracket the true population parameter in approximately $95 \%$ of the cases and $\mathrm{P}=0.05$ which means that the probability of the difference having happened by chance is 0.05 in 1.

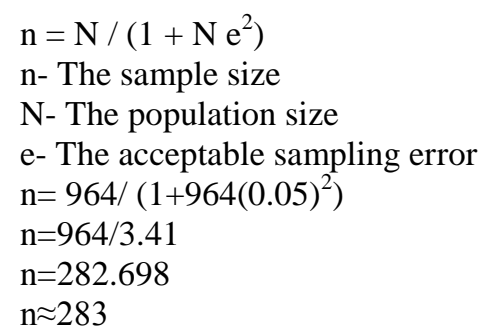

\subsection{Research Instruments}

The research instrument adopted for the study was a closed ended structural questionnaire titled Owners Questionnaire. The researcher used this instrument because of its ability to solicit information from respondents within a short time as supported by Gupta, (1999) as cited in Abeka, (2012). The survey questionnaire was developed based on the research questions and the hypotheses of this study as well as the guidelines recommended for better response outcomes. The questionnaires were divided into two major sections. Item S2 12 was measured based on five point likert scale ranging s2 from 1 . Strongly disagree, to 5 . Strongly agree, developed by RenisLikert. A pilot study for a sample of 10 MSE's was carried out to test the reliability of the instruments.

\subsubsection{Validity of Instruments}

Validity is the ability of an instrument to measure what it sets out to measure (Bryman, 2004 and Yamane, 1967).

Two types of validity were examined in this study namely; face validity and content validity.

Face validity is a measure of the degree to which the instrument is organized. Content validity is a measure to which data collected using an instrument address the specific objectives of study. During the construction of the data collection instrument in this study, validity was ensured through face validity, where the instrument was subjected to two experts to check whether it measured what it was intended to measure and content validity through the view of literature and adapting instruments used in previous research as indicated by the different researchers depicted in the conceptual framework. Also the researcher gave out 20 questionnaires to staff of KCA University Kisumu Campus to help validate it by pointing out ambiguous and unhelpful questions.

\subsubsection{Reliability of Instruments}

In this research study, reliability of the measures was assessed by examining the consistency of the respondents' answers to all items in the measure. Cronbach's alpha reliability coefficients were used to measure the internal consistency of each measure. In order to find out the overall reliability of the each of the latent constructs used in the model, Construct reliabilities were calculated by determining Cronbach's Coefficient Alpha using the following Kunder- Richardson (K-R) 20 formulae;

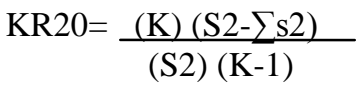

Where:

KR20 = Reliability coefficient of internal consistency

$\mathrm{K}=$ Number of items used to measure the concept

$=$ Variance of all scores

$=$ Variance of individual items

A high coefficient implies that items correlate highly among themselves. This is sometimes referred to as homogeneity of data. Cronbach's alpha estimate value above 0.70 is generally considered as acceptable. According to Sekaran, (2000) as cited in Tossy, (2014), if the value of Cronbach's alpha reliabilities is less than 0.6 , they are considered as poor, if the value is in 0.7 they are acceptable, and the reliabilities value above 0.8 are considered good.

Therefore, the closer the Cronbach's alpha gets to 1.0 the better is the reliability. Table 3.2 presents the Cronbach's alpha coefficients for all constructs obtained in the pretest stage.

Table 3.2. Cronbach's Alpha Coefficients for all Constructs in Pretest Study

\begin{tabular}{cccc}
\hline Items/ Construct & $\begin{array}{c}\text { Cronbach's } \\
\text { Alpha }\end{array}$ & $\begin{array}{c}\text { Cronbach's Alpha Based on } \\
\text { Standardized Items }\end{array}$ & No. of Items \\
\hline Demographic features (DF) & .937 & .927 & 9 \\
Perceived Usefulness (PU) & .873 & .864 & 5 \\
Perceived ease of Use (PEOU) & .958 & .949 & 5 \\
Perceived Risk (PR) & .834 & .808 & 5 \\
Acceptance (MMP) & .805 & .796 & 4 \\
\hline
\end{tabular}

Source: (Field Study, 2016) 


\subsection{Data Collection Procedures}

Research permit was obtained from National Commission for Science, Technology and Innovation through a letter of request from Kisii University on behalf of the researcher and authorization letters from The County Commissioner and The County Director of Education, Kisumu County. The researcher used questionnaires to collect primary data from the respondents. The responses were used to qualify the study's hypotheses.

A paper based survey questionnaire was then prepared and distributed by the researcher with the help of two research assistants to MSE's Owners in Kisumu CBD. The research assistants had completed their undergraduate degrees. They were trained by the researcher on how to administer the questionnaires to the target group. The operational definition or measurement instrument for perceived usefulness, perceived ease of use and the five facets of perceived risk constructs were adapted from Tossy $T$. (2014).

\subsection{Data Analysis}

Data processing and data analysis were guided by the research objectives and theoretical framework for the study. It involves the establishment of categories, the application of the categories to the raw data through coding, tabulation; which leads to drawing statistical inferences. To further supplement the analysis, inferential statistical analysis methods such as regression analysis which includes multiple regression and correlational Pearson product moment coefficient were adopted.

SPSS 20.0 was used to analyze the quantitative data collected from the questionnaires. This software package is widely accepted and used by researchers in different disciplines, thus, this tool has been used to screen the data of this research study in terms of data coding (i.e., using ANOVA) test.

In addition, SPSS was also applied to perform descriptive statistics such as frequencies, percentages, mean values, and standard deviations. These analyses were performed for each variable separately and to summarize the demographic profile of the respondents in order to get preliminary information and the feel of the data. The interpretation of the mean range scale was as follows;

Table 3.3: Interpretation of the mean range scale

\begin{tabular}{rclc}
\hline Mean Range & Response Mode & \multicolumn{1}{c}{ Description } & Interpretation \\
\hline Above 3.75 & Strongly Agree & You agree without doubt & Very High Level \\
$3.74-3.00$ & Agree & You agree with some doubt & High Level \\
$2.99-2.60$ & Undecided & You have doubt/ not sure & Moderate \\
$2.59-2.00$ & Disagree & You Disagree with some doubt & Low Level \\
Below 2.00 & Strongly Disagree & You disagree with no doubt at all & Very Low Level \\
\hline
\end{tabular}

Source; (Field Study, 2016)

Furthermore, before applying Standard Error of the Mean (SEM), SPSS was used to conduct exploratory factor analysis (EFA) for the first stage of data analysis to summarise information from many variables in the proposed research model into a smaller number of factors, which is known as factor / dimension reduction (Abeka, 2012).

Fitness of the model built for this study was examined by standard regression analysis. The analysis showed how much of the total variance in the dependent variable (acceptance of MMP) is possible to explain by the independent variables; demographic features, PU, PEOU, PR and Acceptance of MMP.

Analysis of Variance (ANOVA) was conducted in order to determine the statistical significance of the correlations between demographic features, PU, PEOU, PR and Acceptance of MMP. The p-value of the F-test indicated the level of association between the dependent and independent variables in the model. When the significance $\mathrm{p}$-value is less than 0.05 , it means there is a statistically significant association between the dependent and independent variables. P-value 0.10 refers to weakly significant association.

If the $\mathrm{p}$-value is more than 0.10 , then the model chosen is not statistically significant. ie.

- When;

- P- value $<0.05$ - Statistical Significant association between dependent and independent variables.

- $\mathrm{P}$ - value $=0.10-$ Weak significant association

- P-value> 0.10 - Not Statistically Significant

The Pearson product-moment correlation was also utilized to establish a relationship between demographic features, PU, PEOU, PR and Acceptance of MMP among MSE Owners in Kisumu, Kenya.

The idea for the use of this correlation measure is to find out how much the dependent variables selected (independent variables; demographic features, PU, PEOU and PR) correlate with acceptance of the MMP, and what are their relationships. Also the regression analysis correlations are based on Pearson product-moment correlation. In addition to the automatic 2-tailed significance indicator selected for the analysis, the rules 
Vol. 6, Issue 1, January 2017

for determining the strength of the relationship applied are as presented in table 3.4:

Table 3.4. Strength of relationship based on Pearson correlation

\begin{tabular}{lc}
\hline Pearson correlation & Relationship \\
\hline 0.10 to 0.29 or $-\mathbf{0 . 1 0}$ to $-\mathbf{0 . 2 9}$ & Weak \\
0.30 to 0.49 or $-\mathbf{0 . 3 0}$ to $-\mathbf{0 . 4 9}$ & Medium \\
0.50 to 1.0 or $-\mathbf{0 . 5 0}$ to $-\mathbf{1 . 0}$ & Strong \\
\hline
\end{tabular}

Note, that the negative sign is only referring to the direction of the relationship, not the strength of the relationship. (Abeka, 2012)

To test the hypotheses of this research, the researcher used $z$ and $x^{2}$ statistics at confidence level of $95 \%$. The research hypotheses were put in the form of statistical hypothesis such as $\mathrm{H}_{0}$. With regards to the nature of five-point Likert scale questions, therefore, the researcher tested whether the mean value of each question would be less than or greater than 3 .

Number 3 was the average number of the five choices in each question:

$$
\mu=5 \quad 1+2+3+4+5
$$

Thus, statistical hypothesis was set up as follows:

$\mathrm{H}_{0}: \mu \leq 3$

The Multiple Regression Model was as follows:

$\mathrm{Y}=\mathrm{f}\left(\mathrm{x}_{1}, \mathrm{x}_{2}, \mathrm{x}_{3}, \mathrm{x}_{4}, \mathrm{x}_{5}\right)+\mathrm{e}$

Where:

Y: Acceptance of Mobile Money Application

$\mathrm{X}_{1:}$ Factors of adoption ofMobile Money Application

$\mathrm{X}_{2:}$ Perceived Usefulness (PU)

$\mathrm{X}_{3}$ : Perceived ease of use (PEOU)

$\mathrm{X}_{4}$ : Perceived risk (PR)

$\mathrm{e}=$ Error

\subsection{Ethical considerations}

In doing research, the researcher followed ethical guidelines to ensure that there was no physical or emotional harm to the participants of the research. The researcher avoided plagiarism and falsification of findings while conducting a research.

Last but not least, the researcher was honest in gathering and analyzing data and interpreting the findings; data integrity was of priority. The findings will not be publicized or examined by other qualified researcher by reviewing the original data. Further, all the techniques applied in doing the research were current and appropriate to the current problems. Therefore, by considering the above legal guidelines the researcher avoided legal penalties that compromise the integrity of their work (Bryman, 2004).

\section{RESULTS AND DISCUSSIONS}

Out of a sample of 283 MSE's Owners selected for the study, the researcher managed to collect data from 271 respondents' . This is a response rate of $95.8 \%$ which is acceptable in research, The Journal of American Medical Association as cited in Akhter, (2009) stipulates a sufficient response rate of at least 60\% (JAMA, 2008). The response rate achieved in this study is reasonably much higher than that of earlier similar studies on Mobile money. For instance, the response rate reported in the study by Oye, N. D. at al, (2012) was $87 \%$. According to Mugenda and Mugenda (2003), 50\% response rate is adequate in social science surveys. Further, Saunders et al. (2011) contended that an average response rate between $30 \%$ and $40 \%$ is reasonable for delivery and collection survey method.

The results of participants' demographic characteristics revealed that the majority of the respondents were male $(56 \%)$ in the study (Table 4.7). This was not surprising because looking at the latest gender statistics of Kenya prepared by the Kenya National Bureau of Statistics for the year 2009, it can be seen the total number of male population exceeds slightly the number of females (KNBS, 2009).

The study findings demonstrate that majority of MSE owners are youths in their middle age ranging between 18 years and 45 years old. Youths that fall within this age bracket in the society often act as agents of change (Economist, 2012).Therefore, this result imply that owners of MSEs are young and can easily accept MMP. The findings of this study show the majority of SME owners have experience in business between one and five years. To sum up, the present data analysis suggests that age has an impact on the acceptance of mobile money payments The study findings revealed that majority of MSE owners held Kenya Certificate of Secondary Education (KCSE). This level of education is relatively low. These results are consistent with research of Al-Somali et al. (2012) who found that majority of owners/managers of SMEs held KCSE academic qualification. The low level of education held by the majority of SME owners/managers may contribute to low understanding of the need to accept and use ICT in business. However, this failed to explain the reason for fully embracing MMP in MSEs.

This finding disagrees with the findings of NSBA, (2013) where the highest rate of behavioral intention was noticed regarding those respondents who have a $\mathrm{PhD}$ degree with mean value of 6.33 followed by those who have masters (5.39) and Bachelors (5.37) degrees.

\section{Demographic features:}

The study revealed that only Age and education level are the only influential demographic constructs affecting Acceptance of Mobile Money Payment. Additionally, it also revealed that typical Mobile Money Payment users tend to be well educated and relatively young. The study further revealed that demographic factors have a great impact on consumer attitudes and behavior towards 
acceptance of Mobile Money Payment which confirmed the findings by Karjaluoto, (2012). The MSE Owners' demographic factors were found to have significant relationship with Mobile Money Payment acceptance when tested. This further justifies the fact that there is enormous digital divide within the Kenyan Public.

\section{Perceived Usefulness (PU)}

The respondents' response on Perceived usefulness of mobile banking is shown in Table1. From the table, it is evident that the respondents generally agreed (mean $=4.12$, mode $=4.0$ median $=4$ ) that mobile banking enables them to accomplish their tasks more quickly, it is generally advantageous (mean $=4.25$, mode $=4.02$ median $=4$ ), it makes it easier for them to carry out their tasks and it is useful (mean $=4.227$, mode $=4.0$ median $=4$ ). Furthermore, the findings on hypothesis three indicated that $\mathrm{r}=.645 ; \mathrm{p}$ value $=.000$ suggesting a strong positive relationship between Perceived Usefulness (PU) and acceptance of Mobile Money Payment. This relationship is significant since the $\mathrm{p}$ value $=.000$ is less than 0.05 hence leading to the rejection of the null hypothesis at .05 level of significance.

\section{Perceived Ease of Use (PEOU)}

The results of descriptive statistics on perceived ease of use are displayed from the analysis, requires less mental effort (PEOU1) remains the most appealing factor for acceptance of mobile money payment. This factor has a mean of 4.35. Easy use in task's accomplishment (PEOU2) is another factor for acceptance of mobile money payment with a mean of 4.18. Most respondents were indifferent as to Easy to become skillful (PEOU3) and it requires no formal training (PEUO5) acted as factors for acceptance of mobile money payment. This factors scored means observation of 4.17 and 4.15 in that order. Learning to use is easy (PEOU4) is the least appealing factor for acceptance of mobile money payment. This factor has a mean of 4.11. The findings imply that requires less mental effort, and easy use in task's accomplishment were the dominant constructs with effects on respondents' acceptance behavior of mobile money payment.

However, the overall mean score of the items of this construct was 4.19 , which suggested that the sample very highly agreed that the perceived ease of use of MMP is very high and the technology requires very less mental effort. It is also easy to learn, understand and use, which might suggest higher implications for the acceptance of MMP. PEOU is significant $(\mathrm{P}$ value $=.013)$ in explaining acceptance of mobile money payment. Further it has a strong positive coefficient $(\mathrm{r}=.872)$ indicating a positive correlation with mobile money acceptance

\section{Perceived Risk}

The results of descriptive statistics on Perceived Risk , Application development challenges is the most appealing factor for acceptance of mobile money payment. This factor has a mean of 3.98. Release/loss of critical business data is another factor for acceptance of mobile money payment with a mean of 3.73. Most respondents were indifferent as to whether Identity theft and Human ErrorSending money to wrong account acted as a factor for acceptance of mobile money payment.

This factor scored a mean observation of 3.71 and 3.66 in that order. ERP integration issues is the least appealing factor for acceptance of mobile money payment. This factor has a mean of 3.61 .

The findings show that all items i.e. All the items had mean above 3.5 (i.e. neutral point). The average mean ratings for all the items of this construct were 3.74. This indicated that respondents felt that security risks in MMP is of high concern.This finding also suggested that some respondents had reservations about perceived risk of their personal data in MMP. This was evident from the low mean ratings of risks (3.61) for item PR4 i.e. 'ERP integration issues of MMP". PR is significant in explaining mobile money payment acceptance since $P$ Value $=0.003<005$. However, this influence is strongly negative $(r=-0.548)$.

The composite influence of Independent variables on acceptance of MMP

The findings shows that there is significant joint contribution of demographic features, Perceived Usefulness (PU), Perceived Ease of Use (PEOU) and Perceived risk (PR) on acceptance of mobile money payment. It shows $p=0.0116$ which is less than 0.05 , the relationship is significant. Hence, demographic features, Perceived Usefulness (PU), Perceived Ease of Use (PEOU) and Perceived risk (PR) of the technology significantly contributes to the acceptance of MMP (F = 77.874; $p<0.05)$. Therefore, the question of whether there is joint contribution of demographic features, Perceived Usefulness (PU), Perceived Ease of Use (PEOU) and Perceived risk (PR) on acceptance of MMP among MSE Owners in Kisumu City, Kenya is answered. This position was further strengthened by Multiple Regression Analysis of demographic features, Perceived Usefulness (PU), Perceived Ease of Use (PEOU) and Perceived risk (PR) and Acceptance of MMP. Demographic features, PU, PEOU and PR were jointly found to have a significant contribution on acceptance of MMP $(\mathrm{R} 2=0.7342$, Beta value $=0.167)$ with a Standard Error of Estimate of 0.385 at 1 percent significance level. In other words, an estimated $71.03 \%$ of acceptance of MMP is accounted for by Demographic features, PU, PEOU and PR

\section{CONCLUSION}

The first objective of this study was to establish the influence of demographic features on acceptance of MMP among MSE owners within Kisumu City, Kenya. A sample survey from MSE Owners was conducted to empirically examine this research objective. Data analysis and interpretation revealed two major findings under this objective. It revealed that only Age and education level are the only influential demographic constructs affecting 
Acceptance of Mobile Money Payment. Additionally, it also revealed that typical Mobile Money Payment users tend to be well educated and relatively young. The study revealed that demographic factors have a great impact on consumer attitudes and behavior towards acceptance of Mobile Money Payment which confirmed the findings by Karjaluoto, (2012). The MSE Owners' demographic factors were found to have significant relationship with Mobile Money Payment acceptance when tested. This further justifies the fact that there is enormous digital divide within the Kenyan Public.

The second objective was to establish the relationship between PU and Acceptance of MMP in enterprise management, the results from both descriptive and inferential analysis shows that majority of respondents agreed with the statement that mobile money payment is useful. The finding shows that PU besides demographic factors, PUEO and PR is positively related to acceptance of Mobile Money Payment. The findings of this study are consistent with the findings of previous research conducted in other parts of Kenya including Nakuru Municipality by Oluoch A.R. et al, (2014).

The third objective aimed at establishing the relationship between PEOU and acceptance of MMP. The findings indicate a positive relationship between ease of use and acceptance of Mobile Money Payment. When the four factors are considered in a jointly, PEOU was significant. Descriptive statistics revealed that majority of MSE Owners agreed that Mobile Money payment is easy to use. This is also similar to the findings of studies carried out in other parts of Kenya and other countries.

The fourth objective aimed at establishing the relationship between PR and acceptance of MMP in enterprise management in Kisumu City, Kenya. The study revealed that respondents were hesitant accepting MMP because of risks available; they were uncertain whether they could trust the system with their business and personal data, without hackers or other unauthorized persons accessing their private information. To be more precise, lack of security was found to be a significant obstacle to the acceptance of MMP among the MSE owners in Kisumu city, Kenya. As the amount of products and services offered via the Internet and telephony grows rapidly, customers are more and more concerned about security and privacy issues hence Mobile Money Operators (MNO) must enhance the levels of security available in MMP for them to attract more customers to accept MMP and also it is important for the MNO management to share information, which tells the customers about the greater measure employed to secure the use of MMP.

The fifth objective was to establish the joint contribution of demographic features, PU, PEOU and PR on Acceptance of MMP among MSE owners in enterprise management. The findings shows that $71 \%$ of acceptance is as a result of demographic features, PU, PEOU and PR, demographic features constructs were found to have the highest significant contribution on acceptance to use MMP. This simply means that the higher an individual is educated, the higher his/her capacity to perceive a lot of information; the more likely the users will accept to use MMP because users normally like technology that's effective, efficient, flexible, user friendly and available throughout day and night.

This research is valuable for the Kenya's Mobile banking industry. Findings in this study shed some light for Kenyan M-banking and in particular Mobile Network Operators in terms of implementing Mobile Money Payment strategies by emphasizing the relevant criteria at each phase necessary for a successful acceptance process. From the results, it can be concluded that demographic factors and PU are the most significant factors affecting acceptance of Mobile Money Payment. It's therefore, important for M-payment service providers to emphasize the benefits of Mobile Money Payment technology to the MSE Owners. It can also be concluded PR hinders majority of MSE Owners from accepting it. M-payment service providers and other stakeholders involved in this area should ensure security measures are enforced. Lastly, it can be concluded that there are other factors that affect acceptance of Mobile Money payment. Therefore, more research is required on the factors affecting acceptance of Mobile Money Payment in Kenya.

\subsection{Recommendation}

This study makes significant contributions to knowledge in relation to determinants of MMP acceptance. Furthermore, it also provides an insight into the MSE Owners' needs and wants which may be essential for Mobile Network Operators in order to provide better mpayment services to MSE Owners. In the light of these findings, several recommendations are made which may be useful for Mobile Network Operators and other related authorities.

\section{Recommendation to M-payment Stakeholders}

Mobile Network Operators should a make their customer more aware of the new products or services (Mobile Money Payment) to encourage higher acceptance rate. They can do so by having seminars and exhibitions. Besides this, enlighten and publicity through mass media will also prove to be effective. The researcher also recommends that MMP should be made as user-friendly as possible, easy to use as not many consumers are familiar with command driven menus, especially the older and uneducated generation. MMP should provide customers with the option of choosing their preferred language in order to ease their transactions. The researcher recommend that the MNOs should pay attention to user demographic features, PU,PEOU and PR as all are significantly related to acceptance of MMP. They have also proved to be essential factors that influences acceptance of MMP among MSE Owners in Kisumu City Central Business District.

\section{Recommendation for further research}

This Dissertation has established joint contribution of the factors influencing acceptance of Mobile money payment that provided systematic way to understand acceptance of 


\section{International Journal of Advanced Research in Computer and Communication Engineering} ISO 3297:2007 Certified

Vol. 6, Issue 1, January 2017

MMP by intended users, several beneficial areas for future research, however, remain to be explored.

For example, results of current study are limited to MMP among MSE owners; future research may apply or replicate this study in other domains, such as MSE customers and the business value in Mobile Money Payment. This would be valuable in establishing the external validity of these factors of influence.

In addition, it will be interesting for future research to develop MMP model based on these explored factors in Kisumu City and the rest of the country, Kenya. This will be valuable in providing evidence concerning the robustness of research factors across different cultural settings. It is understood that the robustness of these factors may vary across different cultural settings and thus need to be empirically tested (Mao and Palvia, 2006). When the number of Mobile Money Payment acceptance reaches a critical mass, future studies may examine the factors that contributed to this increase in usage. For example, such a study could take place a year from the date of this study, the study also failed to establish individual contributions of each and every factor of influence on MMP hence future study is vital in establishing this.

In addition, the data for this study was collected using cross-sectional survey, future research is needed to obtain longitudinal data to investigate what factors will influence individuals' perceptions in continuing to use the MMP. Prior literature indicates that individuals' perceptions are formed with the passage of time, experience and continuous feedback from surroundings (e.g. Venkatesh and Davis, 2000; Davis et al., 1989 as cited in Abeka, 2012). Thus, it is expected that the future research will inspect the findings of this research with more in-depth investigations using longitudinal data.

The future study can also propose the other data collection method such as in depth interview with the end user computing. In this study, only questionnaire has been used to collect the data owing to the financial and time constrains. The sample size should also be increased. A larger sample size would be required to enhance generalization ability of research.

\section{REFERENCES}

[1] Abeka, S. O. (2012), Security and Acceptance of Web- Based Marketing Information System among Microfinance Banks in Nairobi Region, Kenya. Accepted to be published in International Journal of Academic Research in Business and Social Sciences, October 2012, Vol. 2, Issue 9 ISSN: 2222-6990.

[2] Akhter, (2009). Talking Back: Empowerment and Mobile Phones in Rural Bangladesh: A Study of the Village Phone Scheme of Grameen Bank. Contemporary South Asia, 12, 3, 327-348.

[3] A.A. Alalwan et al. (2015), Adoption of Mobile Banking in Jordan: Exploring Demographic

[4] Differences on Customers' Perceptions. IFIP International Federation for Information Processing 2015 M. Janssen et al. (Eds.): I3E 2015, LNCS 9373, pp. 13-23, 2015. DOI: 10.1007/978-3-319-25013-7_2

[5] Alliance for Financial Inclusion (AFI). 2010. Case Study: Enabling mobile money transfer. The Central Bank of Kenya's treatment of M-Pesa. Retrieved March 19, 2014 from http://www.gsma.com/ mobilefordevelopment/wpcontent/uploads/2013/09/enablingmobile mneytransfer92.pdf.

[6] Al-Somali et al, (2012) .Understanding the Characteristics of Early and Late Adopters of Technology: The Case of Mobile Money. International Journal of Eservices and Mobile Applications (IJESMA), 4(2), 37-54.

[7] Appiah: Agyemang F. (2006). Electronic Retail payment systems: User Acceptability and Paymentproblems in Ghana. School of Management Business Administration Blekinge Institute of technology, Sweden.

[8] Au and Kauffman, (2008). The economics of mobile payments: understanding stakeholder issues for an emerging financial technology application.Electronic Commerce Research andApplications, 7,141-164.

[9] Balocco, Mogre, \&Toletti, (2009). Mobile Internet and MSEs: A Focus on the Adoption, Industrial Management \& Data Systems, 109 (2), 245-261.

[10] Banks, (2008). Adoption of Electronic Invoicing in MSEs. Master's thesis, Lulea University of Technology, Sweden: Obituary Press.

[11] Bryman, (2004) Social Research Methods. (2nded) Oxford: Oxford University Press.

[12] CBK. (2003) and CBK. (2007). Payment Systems in Kenya. Central Bank of Kenya annual financialreport for the year, Kenya.

[13] CBK. (2008). Payment Systems in Kenya. Central Bank of Kenya annual financial report for the year,Kenya.

[14] Cheah, C. M., Teo, A. C., Sim, J. J., Oon, K. H. and Tan, B. I. (2014). Factors Affecting Malaysian Mobile Banking Adoption: An Empirical Analysis, International Journal of Network andMobile Technologies, Vol. 2, Issue 3, pp. 149-160.

[15] Communications Authority of Kenya (CAK). (2014). Annual Report 2012-2014, Retrieved

[16] September4,2014from:http://www.ca.go.ke/images//downloads/PU BLICATIONS/ANNUA REPORTS/Annu al\%20Report $\% 20$ for $\%$ 20the\%20Financial\%20Year\%202012-2013.pdf.

[17] Communications Commission of Kenya (CCK). (2014). Annual Report 2012-2013, Retrieved September 4, 2014 from: http://www. ca.go.ke/images//downloads/PUBLICATIONS/ANNUAREPORTS /Annual\%20Report\%20for\%20the\%20Financial\%20Year\%202012 -2013.pdf.

[18] Computerworld (2012). Trend Watch: Google says mobile payments growing fast but won't catch on overnight. Computer World, Retrieved November 2, 2012 from

[19] http://www.computerworld.com/s/article/9232637/Google_says_m obile_payments_growing fast_but_won_39_t_catch_on_overnight.

[20] Davis, F. D. (1989), User Acceptance of Computer Technology: a Comparison of Two Theoretical Models, Management Science, Vol. 35, No. 8,

[21] Davis, F. D \& Venkatesh. V. (1996a) A critical assessment of potential measurement Biases in the technology acceptance model: three experiments, Int . J . Human - Computer Studies, Vol. 45 pp. 19-45, Davis, F. D \&Venkatesh, V. (1996b) A model of the antecedents of perceived ease of use: Development and test, Decision Sciences, Vol. 27, No. 3 pp. 451-481.

[22] Duane, \& O'Reilly, \& Andreev, (2014). Realizing M-Payments: modeling consumers' willingness to M-pay using Smart Phones. Behavior\& Information Technology, 33:4, 318-334, DOI: 10.1080/0144929X.2012.745608

[23] Etim, (2012). The emerging market of Sub-Saharan Africa and technology adoption: Features user's desire in mobile phones. International Journal of ICT Research and Development in Africa. 3(1), 14-16

[24] Etim, Alice, (2013). Mobile technology adoption for microfinance delivery in Sub-Saharan Africa. Research in Business \& Economics Journal (RBEJ), 7, from http://www.aabri.com/rbej.html.

[25] Etim; Alice, (2011). Bottom-up business development: Empowering low income societies throughmicrofinance and mobile technologies.International Journal of Humanities \& Social Sciences, 1(13), 1-11.

[26] Hakkila, J. \&Chatfield,C. (2005). Analysis of the factors influencing consumers' intention to use mobile money in Nigeria. Unpublished MSc Thesis, University of Glamorgan. Pousttchi, K., \&Wiedemann, D. G. (2007). What influences consumers' intention to use mobile payments? LA: Global Mobility Round Table. 


\section{International Journal of Advanced Research in Computer and Communication Engineering} ISO 3297:2007 Certified

Vol. 6, Issue 1, January 2017

[27] Holmes, (2011). Card and mobile payment opportunities: A framework to consider potential winners and losers and a snapshot of the future payments landscape in Africa. Journal of PaymentsStrategy and Systems, 5(2), 134-142.

[28] International Financial Corporation (IFC). (2013). Kenya Country Profile, 2013. Enterprise Surveys, Retrieved April 9, 2014 from http://www.enterprisesurveys.org.

[29] Karjaluoto, (2012). Retrieved September 28, 2014. Disruptive Mobile Banking in Kenya, Slim SIMs. Web page blog. from http://www.economist.com/blogs/baobab/2014/09/disruptingmobile banking-kenya.

[30] Kinyanjui, K. (2009). M-Pesa goes global in battle for mobile cash transfer pie. Retreived

[31] on20/10/2011 from Business Daily, Nairobi, Kenya Web site: http://allafrica.com/stories/200910121448.html

[32] Kisumu County, ( 2014); County Development plan, retrieved from Kisumu County website.Kisumu Regional Office.

[33] KNCCI, (2014). Registered Micro and Small Enterprises in Kisumu City: Retrieved from theirdatabase in Kisumu Regional head office.

[34] Kumar, (2005) ,Mobile money: The economics of M-PESA, NBER Working Paper, No. 16721.Retrieved August 2, 2012 from http://www.microfinancegateway.org/gm/document$1.9 .49758 /$ mobile_money.pdf.

[35] Lai, S.V. \& Li, H., (2004), 'Technology acceptance model for internet banking: an invariance analysis', Information \& Management, Article in press, accepted 21 January 2004.

[36] Lee, M. (2009). Factors influencing the adoption of internet banking: An integration of

[37] TAM andTPB with perceived risk and perceived benefit. Electronic Commerce Research and Applications, 8(3), 130-141. doi:10.1016/j.elerap.2008.11.006

[38] Mas, Ignacio (2010), Mobile Payments Go Viral: M-PESA in Kenya, in Yes Africa Can: SuccessStories from a Dynamic Continent, World Bank, Washington D.C

[39] Masinge, (2010).Factors Influencing the Adoption of Mobile Banking Services Bottom of thePyramid in South Africa, A Research Report submitted to the Gordon Institute of BusinessScience, University of Pretoria, South Africa.

[40] Matere, (2010). LEO: Bridging the Digital Divide one village to another and the world. Retrievedfrom http://arc.peacecorps connect.org on 20/01/2012

[41] Maxwell, J., \& Miller, B. (n.d.). Two aspects of thought and two components of qualitative dataanalysis.Unpublished manuscript.

[42] McCole, and Ramsey, (E. 2005). A profile of adopters and nonadopters of E-Commerce in SMEprofessional service firms. Australasian Marketing Journal 13(1): 36-48.

[43] Molla, and Licker, (2005). E-commerce adoption in developing countries: a model and instrument. Information\& Management 42: 877-899.

[44] Morgan, (2012). Private sector development: What's next for mobile money? The World Bank, http://blogs.worldbank. org/psd/what-s-next-for-mobile-money-0.

[45] Mugenda, O. \&Mugenda, A. (1999). Research Methods: Quantitative and Qualitative Approaches.Nairobi: Acts press.

[46] Mulupi, (2011). Retrieved: 17th November 2012. Kenya: Taking Mobile Money a Step Further.Nairobi. Retrieved from www.audiencespace.org field blog.

[47] Ng'ang'a; Kosgei; and Gathuthi, (2009). Fundamentals of Management Research Methods- Nairobi: Macmillan Kenya (Publishers) Limited. ISBN 9789966343451

[48] NSBA, (2013) Small Business Technology survey in Kenya Retrieved from: https://www.google.com/url?sa=t\&rct=j\&q=\&esrc $=$ s\&source $=$ web $\& \mathrm{~cd}=3 \& \mathrm{cad}=$ rja $\&$ uact $=8 \&$ ved $=0$ ahUKEwi3lavA6 4TPAhUHWBoKHZwPC6EQFggpMAI\&url=http $\% 3 \mathrm{~A} \% 2 \mathrm{~F} \% 2 \mathrm{Fw}$ ww.nsba.biz\%2Fwp-content\%2Fuploads\%2F2013\%2 F09\%2F Technology-Survey-2013.pdf\&usg=AFQjCNHU-gnVnlIqwQMx ggSkUXE-4ZmElQ \&sig2=9TDGLO3bIutTinJcy94T6A\&bvm=bv.132479545,d.d2s

[49] Oluoch A.R. et al, (2014).Factors affecting adoption of mobile banking technology in Kenya. A case of bank customers within Nakuru Municipality. Asian Journal of Business and ManagementSciences ISSN: 2047-2528 Vol. 2 No. 11 [01-13]

[50] Orodho, (2002). Techniques of Writing Research Proposals and Reports in Education and Social Sciences.Nairobi: Masola Publishers.
[51] Oye, N. D. at al, (2012) Acceptance and Usage of ICT by University Academicians Using

[52] UTAUT Model: A Case Study of University of Port Harcourt, Nigeria.Journal of Emerging Trends in Computing and Information Sciences.

[53] Rudl, (n.d.). Retrieved December 04, 2010, Payment Options for Online Shoppers: Other OnlinePayment, Other Online Payment Options. From http://www.entrepreneur.com/article.html: http://www.entrepreneur.com

[54] The Economist (2012). Mobile Money in Africa - Press 1 for modernity: One business where thepoorest continent is miles ahead. The Economist, April 28, 55.

[55] Titus Tossy, (2014) Modelling the Adoption of Mobile Payment System for Paying Examination Fees in Tanzanian Major Cities. International Journal of Computing and ICT Research, Vol. 8,Issue 2 pp 83-98. http://ijcir.mak.ac.ug/volume8issue2/article7.pdf

[56] Tobbin, (2010) "Modeling Adoption of Mobile Money Transfer: A Consumer Behavior Analysis"Proceedings of the 2nd International conference on M4D Mobile Communication Technology for Development M4D at Kampala, Uganda

57] Tobbin, (2012). The Adoption of 'Transformational Mobile Banking' by the Unbanked:An Exploratory Field Study. Communications and Strategies, (86), 103-120.

[58] Tobbin, (2012). Towards a model of adoption in mobile banking by the unbanked: a qualitative study.Info, 14(5), 74-88.use: Development and test, Decision Sciences,Vol. 27, No. 3 pp. 451481.

[59] Venkatesh, V., Morris, M. G., Davis, G. B. \& Davis, F. D. (2003). User acceptance ofinformation technology: Toward a unified view. MIS Quarterly, 27(3), 425-478.

[60] Wu, (2015) Understanding Mobile Money Ecosystem: Roles, Structure and Strategies. In MobileBusiness (ICMB), Tenth International Conference on (pp. 185-194). IEEE.

[61] Yamane, (1967) .Quantitative Data Analysis with SPSS12 and 13: A Guide for Social Scientists. East Sussex: Routledge.

\section{BIOGRAPHIES}

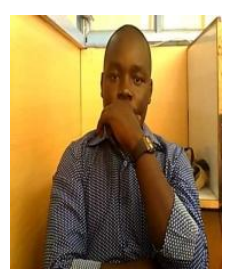

Edwin Omol holds Masters of Science in Information Systems from Kisii University, Bachelors of Science and Diploma in Information Technology from KCA University and; CISCO-ITE $(\mathrm{A}+)$ and $\mathrm{CCNA}$ certified. He has been involved in a number of research projects of ICTs and development, including eMoney project, E-learning systems, Technology Acceptance, Mobile Technology, Management Information Systems, Routing and Switching, Web- Design, E- Commerce and E-exam management in Kenya. Besides, he has published widely in journals and conference proceedings in Information technology and ICTs for development. Moreover he's a diligent and hardworking young man who is self-motivated.

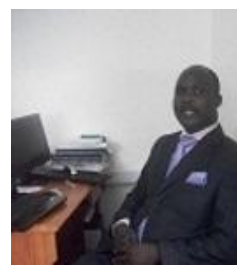

Dr. Silvance Abeka is currently a Senior Researcher and dean, School of Informatics and Innovative Systems, Jaramogi Oginga Odinga University of Science \& Technology and previously dean- Faculty of Applied Science and Technology and also a senior Lecturer at Kampala International University- Dar es Salaam Collage in the Department of Computer Studies. He holds $\mathrm{PhD}$ in Management Information System (MIS) and Master's degree in Business Administration (Information 
Technology), from Kampala International University Dar es Salaam Collageand; Masters of Science in Computer Science from University of Dares Salaam. His research interests include IT innovation adoption, open source software study, and IT offshoring, Management Information Systems, Principles of Statistics, Web- Design and E- Commerce.

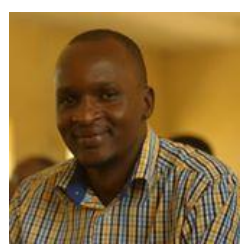

Fred Wauyo holds MBA. In Information Technology from Kampala International University, BSc in Information Technology from Islamic University in Uganda. And Diploma in Computer and Information Technology from Islamic University in Uganda and CCNA and Certified Cisco Instructor from Makerere University Uganda, Oracle Certified Associate. He has done research projects of ICTs and Intelligence Technologies, including, E-learning systems, writing Mob Applications, IT innovation and absorptive capacities of users, open Source Software study, Management Information Systems, Routing and Switching, Web Content developments of Dynamic Websites, Information Technology Administration through Linux and Ubuntu. Programming Skills in Java, $\mathrm{C} / \mathrm{C}++, \mathrm{PhP}$ and Pearl and self- driven. 